\title{
Associations Between Exposure to Domestic Violence, Depression and Cyberbullying Among Secondary School Adolescents
}

\author{
Bede Chinonye Akpunne, A. Opadere Ayodele, Stephen Ishola Babatunde, Joshua Oludare Ogunsemi, \\ and C. David Ndubisi
}

\begin{abstract}
Literatures on high prevalence of domestic violence are well documented. There is however paucity of research on exposure to domestic violence relates to cyber bullying behavior among Nigerian adolescents. The focus of this study was to determine the correlation between Exposure to Domestic Violence (EDV), depression and cyber bullying behavior among secondary school adolescents. A total of $\mathbf{3 0 0}$ purposively selected secondary school adolescents in Oshodi Isolo, Lagos metropolis Nigeria responded to Child Exposure to Domestic Violence Scale (CEDV), Centre for Epidemiological Studies Depression Scale for Children (CES-DC) and Online Victimization Scale for Adolescents (OVSA). Data was analyzed using the Statistical Package for Social Sciences (SPSS). Data was analyzed using the descriptive (frequency count) and Inferential statistics (Pearson moment correlation analysis). A high prevalence of EDV, depression and involvement of cyber bullying was reported. Patterns of the factors of cyberbullying ranged from $26.7 \%$ individual online racial discrimination to $37 \%$ vicarious online racial discrimination. EDV significantly positively related to depression and involvement in cyber bullying. Significant gender influence was observed on depressing and cyber bullying. Age categories significantly influenced cyber bullying. Authors conclude that a high prevalence of depression and involvement in cyber bullying exists among secondary school adolescents. EDV is a significant positive correlate of depression and cyber bullying. There is gender difference on depression and cyber bullying. Age categories influence cyber bullying among the adolescents.
\end{abstract}

Index Terms - Domestic violence, depression, cyber bullying adolescents.

\section{INTRODUCTION}

Belsey [1] explained Cyber bullying (CB) as involving the use of information and communication technologies (ICT) to aid deliberate, repeated, and aggressive behavior by an individual or group that is intended to harm others. CB can be defined as a series of recurring, intentionally aggressive behaviors that is carried out by a group or individual using electronic means, focused on threatening, embarrassing, or intimidating a victim who cannot easily defend himself or herself [2]. Willard, [3] categorized forms of cyber bullying into the following:

Published on July 17, 2020

Bede Chinonye Akpunne, Redeemer's University, Nigeria.

(e-mail: akpunneb@ run.edu.ng)

A. Opadere Ayodele, Redeemer's University, Nigeria.

(e-mail: opaderea ${ }^{\circledR}$ run.edu.ng)

Stephen Ishola Babatunde, Obafemi Awolowo University, Nigeria.

(e-mail: babatundekayode123@gmail.com)
1) Flaming which involves sending angry, rude, vulgar messages directed at a person or persons privately or to an online group.

2) Harassment (repeatedly sending a person offensive messages.

3) Cyber stalking: a form of harassment that includes threats of harm.

4) Denigration (put-downs) Sending or posting harmful, untrue, or cruel statements about a person to other people.

5) Masquerade (pretending to be someone else and sending or posting material that makes that person look bad or places that person in potential danger).

6) Outing and trickery (Sending or posting material about a person that contains sensitive, private, or embarrassing information, including forwarding private messages or images. Engaging in tricks to solicit embarrassing information that is then made public.

7) Exclusion (actions that purposely and intentionally exclude a person from an online group).

Cyber bullying has the tendency of devastating victims and their families. Just like the traditional bullying, CB can result in psychological harm as low self-esteem, school failure, anger, anxiety, depression, school avoidance, school violence, and suicide [4].

World Health Organization (WHO) [5] has defined Domestic Violence (DV) as the range of sexually, psychologically and physically coercive acts used against women by current or former male intimate partners.

Domestic Violence occurs globally [6] and can take many forms, including physical aggression or assault (hitting, kicking, biting, shoving, restraining, slapping, throwing objects, battering), or threats thereof. It can also take the form of sexual abuse; emotional abuse; controlling or domineering; intimidation; stalking; passive covert abuse and economic deprivation [7]. Incidents of Domestic Violence (DV) include honor beating, torture, acid baths and even death through honor killing battering of intimate partner and others, sexual abuse of children, marital rape and traditional practices that are harmful to women such as female genital mutilation [8], [9].

Witnessing abuse, experiencing it or living in an environment where someone is being physically abused can

Joshua Oludare Ogunsemi, Redeemer's University, Nigeria.

(corresponding e-mail: ogunsemio ${ }^{\circledR}$ run.edu.ng)

C. David Ndubisi, Redeemer's University, Nigeria.

(e-mail: blendsfashion@ ${ }^{@ m a i l . c o m) ~}$ 
be psychologically devastating for a child and makes such a child susceptible to depression, leaving people around him and his immediate environment unsafe. Children who are exposed to Domestic Violence (DV) during their upbringing will suffer in their developmental and psychological wellbeing [10]; [11]. Exposure to Domestic Violence (DV) generally impacts how the child develops emotionally, socially, behaviorally as well as cognitively [11], [12]. Some emotional and behavioral problems that can result due to domestic violence includes increased aggressiveness, anxiety, and changes in how a child socializes with friends, family, and authorities [10], [12]. Studies showed that children who experienced domestic violence had psychopathological symptoms such as depressive symptoms, anxiety problems and personality problems [13]-[15]. In this study our aim is to ascertain the Patterns of the factors of cyber bullying, Find out the relationship between Exposure to Domestic Violence (EDV), depression and involvement in cyber bullying, observe the gender difference on depression and cyber bullying, and determine the influence of Age categories on cyber bullying.

A. Research Questions

1. What are the Patterns of the factors of cyber bullying among the participants?

2. Are there significant relationships between EDV, depression and involvement in cyber bullying?

3. What are the gender differences in depression and cyber bullying?

4. Does age play significant influence on cyber bullying?

\section{B. Hypotheses}

1. Perceived exposure to domestic violence will significantly relate with the severity of depression among the participants

2. Perceived exposure to domestic violence will significantly relate with the severity of general online victimization among the participants.

3. There will be significant gender difference on severity of depression among selected secondary school adolescents in Lagos state.

4. There will be significant gender difference on General online victimization among selected secondary school adolescents in Lagos state.

5. There will be significant influence of age categories on General online victimization among selected secondary school adolescents in Lagos state.

\section{RESEARCH METHOD}

\section{A. Participants}

A cross sectional survey design was employed in the study. The population comprised of male and female senior secondary school (SSS) students in selected school in Oshodi-Isolo LGA Lagos state Southwestern Nigeria. Multistage sampling technique was adopted in this study. In the first stage a purposive sampling technique was used in selecting the five schools. Also a purposive sampling technique was used to draw 75 students from each of the selected senior secondary schools who participated in the study.

\section{B. Measures}

Three standardized research instruments were used for the data collection. They are: Child Exposure to Domestic Violence Scale (CEDV). This is a 26-item instrument by Edleson [16] that measure Childs exposure to domestic violence. Center for Epidemiological Studies Depression Scale for Children (CES-DC) is a 20 item self-report depression inventory by Weissman, Orvaschel and Padian [17]. Online Victimization Scale for Adolescents [18] is a four factor scale (general online victimization (8 items), direct sexual online harassment (6 items), direct racial discrimination (4 items) and vicarious racial discrimination (3 items).

\section{Psychometric Properties of the Instruments}

The Child Exposure to Domestic Violence Scale (CEDV) has a Cronbach Alpha Coefficient ranging from .59 to .85 . The Online Victimization ranged from .47 to $.79(\alpha=.88)$, Online Sexual Victimization ranged from .50 to $.84(\alpha=.83)$, Individual Online Racial Discrimination ranged from .64 to $.70(\alpha=.71)$, and Vicarious Racial Discrimination ranged from .74 to $.82(\alpha=.83)$. The Center for epidemiological studies depression scale for children (CES-DC) scale has an internal consistency $(\alpha=.84-.92)$ and excellent concurrent validity with the Children's Depression Inventory.

\section{Data Analysis}

Data collected was analyzed with the use of Statistical Package for Social Sciences (SPSS). Descriptive statistics (frequency count and percentages) were used to organize, summarize and describe the demographic characteristics of respondents; inferential statistics (t-test of independent variables, Pearson moment correlation analysis were used to test the hypotheses of the study.

\section{RESULTS}

\section{A. Demographic Characteristics of Participants}

Distribution of respondents by sex shows that $146(48.5 \%)$ were male while 154 (51.5\%) were female. Distribution by age categories shows that $176(58.7 \%)$ were between ages 13 15 years old, while $124(41.3 \%)$ were between the age categories of 16-20 years.

Furthermore, summary of distribution by religion show that that $262(88.5 \%)$ of the respondents were Christians, while $34(11.5 \%)$ were Muslims. $209(69.7 \%)$ were from monogamous families while 91 (30.3\%) were from polygamous family type. Distribution by caregivers' shows that both participants living with parents were 218 (83.5\%), 6 $(2.3 \%)$ live with their fathers only, $23(8.8 \%)$ are with mothers only while those with relations are $14(5.4 \%)$. The frequency of the caregivers' occupation are divided into 3 groups in which civil servant has a frequency of 119 (44.4), business man/woman 127 (47.4) and artisan 22 (8.2). 


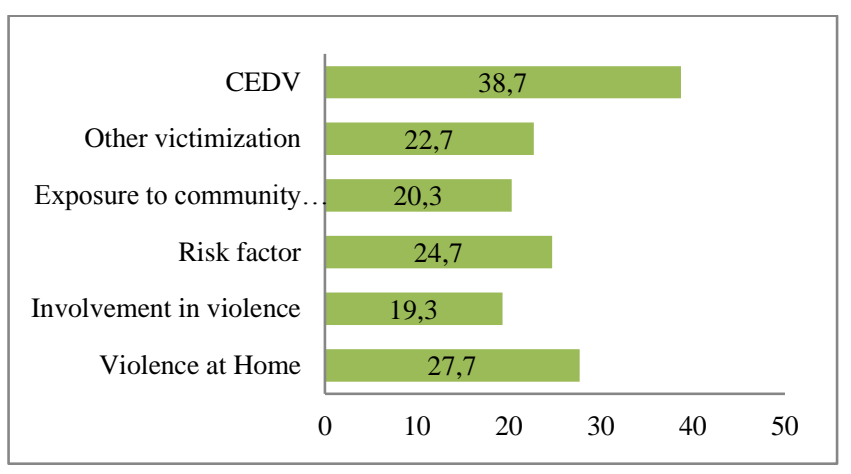

Fig 1. Patterns of exposure to domestic violence among Nigerian adolescents.

Fig. 1 reveals the patterns of perceived child exposure to domestic violence among the participants. The summary of figure shows that prevalence of the factors Child Exposure to Domestic Violence (CEDV) ranges from $19.3 \%$ of involvement in violence to $27.7 \%$ of risk factor. While the overall prevalence of CEDV among the participants was $38.7 \%$. This report shows that there is a high rate of perceived exposure to domestic violence among the participants.

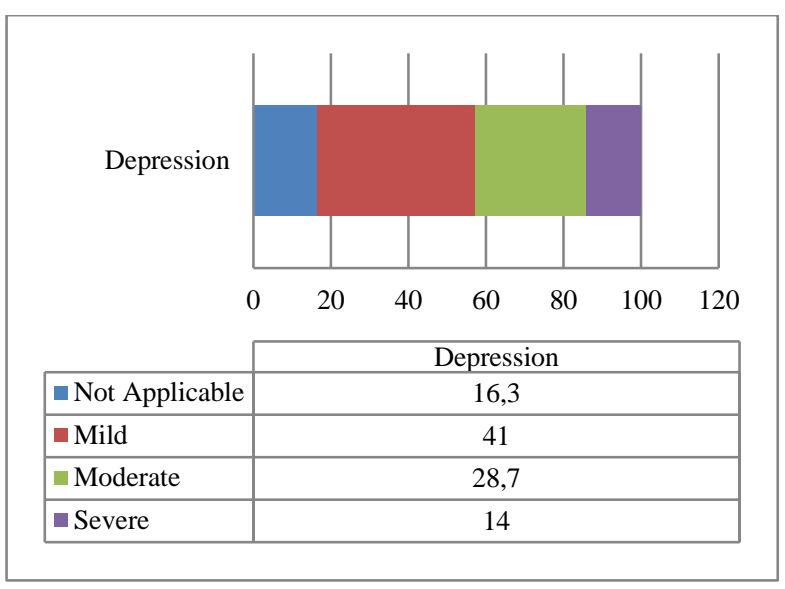

Fig. 2. Prevalence of depression among the adolescents.

Fig. 2 shows the pattern of depression among the participants. It shows that $28.7 \%$ show moderate level of depression while $14.0 \%$ report severe level of depression. This result shows a high prevalence of depression among the adolescents.

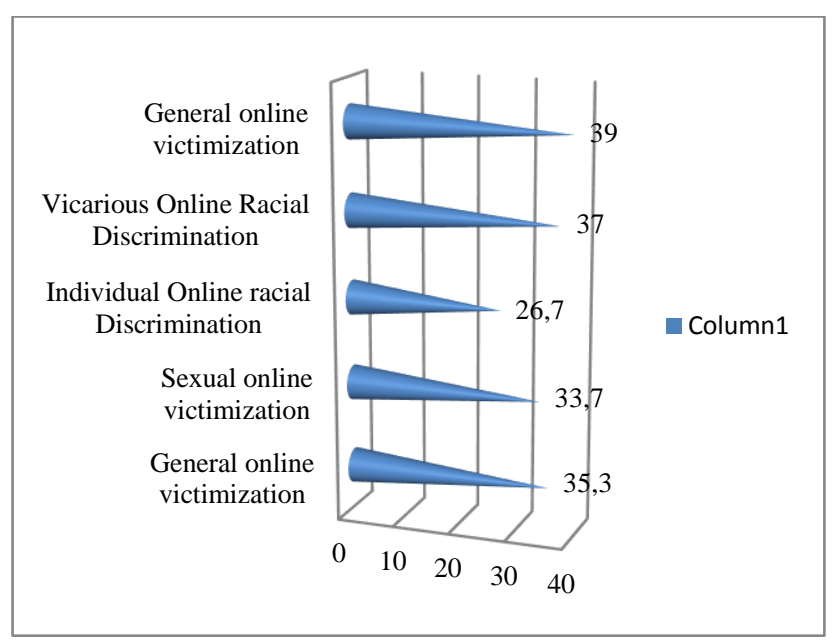

Fig. 3. Patterns and prevalence of cyber victimization among Nigerian adolescents.
Fig. 3 reveals the patterns of perceived online victimization among the participants. The summary shows that prevalence of the sub scales of online victimization ranges from $26.7 \%$ of Individual Online Racial Discrimination (IORD) to $37.0 \%$ of Vicarious Online Racial Discrimination (VORD). While the overall prevalence of online victimization among the participants was $39.0 \%$. This result shows that there is a high rate of perceived online victimization among the participants.

\section{B. Test of Hypotheses}

Hypothesis One. Perceived exposure to domestic violence will significantly relate with the severity of depression among the participants.

The hypothesis was tested by conducting a Pearson Product Moment Correlations (PPMC) setting the level of significant at 0.05 . Respondent scores on CEDV and the corresponding scores on severity of depression was subjected to a relationship test. The analysis result is summarized and presented in Table 1

TABLE 1:. PEARSON'S CORRELATION ANALYSIS OF PERCEIVED EDV AND SEVERITY OF DEPRESSION.

\begin{tabular}{|c|c|c|c|}
\hline Variable & $\mathbf{N}$ & $\mathbf{r}$ & $\mathbf{p}$ \\
\hline $\begin{array}{l}\text { Perceived Exposure to } \\
\text { domestic violence }\end{array}$ & 3000 & $.407 * * 0$ & .000 \\
\hline
\end{tabular}

The analysis summary in Table 1 indicates that there is a statistically significant positive correlation between perceived exposure to domestic violence and severity of depression among the respondents $\{\mathrm{r}=.407, p=.000\}$. This result reveals that the more the exposure to domestic violence the higher the severity of depression among the participants.

Hypothesis Two. Perceived exposure to domestic violence will significantly relate with the severity of general online victimization among the participants.

The hypothesis was tested by conducting a Pearson Product Moment Correlations (PPMC) setting the level of significant at 0.05 . Respondent scores on EDV and the corresponding scores online victimization was subjected to a relationship test. The analysis result is summarized and presented in Table 2.

TABLE 2: PEARSON'S CORRELATION ANALYSIS OF EDV AND

\begin{tabular}{lllll}
\multicolumn{5}{c}{ ONLINE VICTIMIZATION. } \\
\hline Variable & \multicolumn{1}{c}{$\mathbf{N}$} & $\mathbf{r}$ & $\mathbf{p}$ \\
\hline $\begin{array}{l}\text { Perceived Exposure } \\
\text { domestic violence }\end{array}$ & & 300 & $.493^{* *}$ & .000 \\
** correlation is significant at the 0.01 level (2 tailed) &
\end{tabular}

The analysis summary in Table 2 indicates that there is a statistically significant positive correlation between perceived exposure to domestic violence and general online victimization among the respondents $\{\mathrm{r}=.493, p=.000\}$. This result reveals that the more the exposure to domestic violence the higher the online victimization among the participants.

Hypothesis Three. There will be significant gender difference on severity of depression among selected secondary school adolescents in Lagos state.

The hypothesis was tested by conducting an independent samples t-test at 0.05 level of significant. Respondent gender 
was compared based on their scores on depression. The analysis result is summarized and presented in Table 3.

TABLE 3: INDEPENDENT SAMPLES T-TEST OF GENDER DIFFERENCE ON SEVERITY OF DEPRESSION

\begin{tabular}{lllllll}
\hline Variables & Gender & N & Mean & SD & t & p \\
\hline Depression & Male & 145 & 16.30 & 8.66 & - & .005 \\
& Female & 154 & 19.39 & 10.29 & 2.81 & \\
\hline
\end{tabular}

The analysis summary in Table 3 shows that there is a statistically significant gender influence on severity of depression among the participants $\{\mathrm{t}(300)=-2.81, \mathrm{p}=.005\}$. The result of the analysis shows the females' participants have higher mean scores in the severity of depression than their male counterparts suggesting the female adolescent manifested higher severity of depression than male participants.

Hypothesis Four. There will be significant gender difference on General online victimization among selected secondary school adolescents in Lagos state.

The hypothesis was tested by conducting an independent samples t-test at 0.05 level of significant. Respondent gender was compared based on their scores on general online victimization. The analysis result is summarized and presented in Table 4.

TABLE 4: INDEPENDENT SAMPLES T-TEST OF GENDER DIFFERENCE ON GENERAL ONLINE VICTIMIZATION

\begin{tabular}{llccccl}
\hline Variables & Gender & N & Mean & SD & t & p \\
\hline General & Male & 145 & 33.72 & 13.9 & - & 0.028 \\
$\begin{array}{l}\text { online } \\
\text { victimization }\end{array}$ & Female & 154 & 30.62 & 9.7 & 2.21 & \\
\hline
\end{tabular}

The analysis summary in Table 4 shows that there is a statistically significant gender influence on general online victimization among the participants $\{\mathrm{t}(300)=-2.21$, $\mathrm{p}=.028\}$. The result of the analysis shows the male participants have higher mean scores in general online victimization than their female counterparts suggesting the male adolescent were more involved in general online victimization than female participants.

Hypothesis Five. There will be significant age categories on General online victimization among selected secondary school adolescents in Lagos state.

The hypothesis was tested by conducting an independent samples t-test at 0.05 level of significant. Respondents' age categories were compared based on their scores on general online victimization. The analysis result is summarized and presented in Table 5.

TABLE 5: INDEPENDENT SAMPLES T-TEST OF AGE CATEGORIES DIFFERENCE ON GENERAL ONLINE VICTIMIZATION

\begin{tabular}{lllllll}
\hline Variables & $\begin{array}{l}\text { Age } \\
\text { categories }\end{array}$ & N & Mean & SD & t & p \\
\hline $\begin{array}{l}\text { General } \\
\text { online } \\
\text { victimization }\end{array}$ & $\begin{array}{l}\text { years } \\
16-20\end{array}$ & 15 & 30.16 & 11.2 & -3.36 & .001 \\
& $\begin{array}{l}13-24 \\
\text { years }\end{array}$ & 124.92 & 12.7 & & \\
\hline
\end{tabular}

The analysis summary in Table 5 shows that there is a statistically significant difference in age categories on general online victimization among the participants $\{\mathrm{t}(300)=-3.36$, $p=.001\}$. The result of the analysis shows that participants within age categories of $16-20$ years have higher mean scores in general online victimization than age categories 13 - 15 years suggesting the late adolescents reported more victims of general online victimization than earlier adolescents.

\section{DISCUSSIONS}

A high prevalence of depression and cyber bullying behaviour was observed in this study. This finding is in agreement with previous studies. For instance in a prevalence study of depression among Nigerian children, Chinawa, Manyike, Obu, Aronu, Odutoa and Chinawa [19] reported a $7.4 \%$ rate of severe depression among 12 years old Nigerian children; Umeh [20] returned a $32.1 \%$ prevalence rate while Okwaraji, Aguwa, Onyebueke Shiweobi-Eze [21] reported that $20.0 \%$ and $4.5 \%$ of the undergraduates were found to be mildly and moderately depressed respectively. Among Indian adolescents the prevalence of depression was found to be $49.2 \%$ out of which $7.7 \%$ were severe depression [22]. In a similar study among Indian population, Kumar and Akoijam [23] found an $81.6 \%$ prevalence of depression. Among Malaysian adolescents Ramli, Adlina, Suthahar, Edariah, Ariff, Narimah, Nuraliza, Fauzi and Karuthan [24] reported a $10.3 \%$ prevalence of depression.

Among Spanish secondary school students Barrio, Dios, Montero, Martin, Ochaita, Espinosa, Gutierrez and Barrios [25] reported a $41.4 \%$ prevalence of cyber bullying. Bulut and Alci [26] reported a high rate of cyber bullying among secondary students in Istanbul. Among Indonesian adolescents Safaria [27] returned an $80 \%$ of the participants reported to have experienced cyber bullying, as well as being perpetrators of cyber bullying almost every day. Among Nigerian students Kingsley, Ementa and Ejikeme [28] reported a prevalence range of between $48 \% 57 \%$ who have been bullied through the various cyber media. In another Nigerian study Owuamanam and Makinwa [29] found that $28 \%$ of sampled students were victims while $42 \%$ were perpetrators cyber bullying.

Result of the first hypothesis showed that there is a statistically significant positive correlation between perceived exposure to domestic violence and severity of depression among the respondents. This finding is supported by previous studies [14], [15], [30]-p32]. Children who witness fewer incidents of violence and experience positive interactions between caregivers may be, for instance, less detrimentally impacted than those exposed to frequent and extreme aggression. The psychological aftermath of exposure to DV can include fear of harm or abandonment, excessive worry or sadness, guilt, inability to experience empathy or guilt, habitual lying, low frustration tolerance, emotional distancing, poor judgment, shame, and fear about the future which leads to major depression [32].

The result of the second hypothesis revealed that there is a statistically significant correlation between perceived exposure to domestic violence and general online victimization among the respondents. This result reveals that the more the exposure to domestic violence the higher the online victimization among the participants in which an article by Kothari [33] stated that children who witness domestic violence are at a much higher risk of becoming both bullies and victims of bullying. 
Furthermore the result showed that there is a statistically significant gender influence on severity of depression among secondary school adolescents. Female adolescent were found to manifest higher mean score in severity of depression than male participants. This finding is supported by Kumar and Akoijam [23], Jha, Singh and Aggrawal [22], Borchard, [34] and Chinawa, et al [19]. Depression is about twice as common in women as in men, with about 1 in 4 women suffering from depression at some point during her lifetime.

The result of the fourth hypothesis showed that there is a statistically significant gender influence on general online victimization among the participants. The analysis shows the male participants have higher mean scores in general online victimization than their female counterparts suggesting the male adolescent were more involved in general online victimization than female participants. The finding is supported by Maclean, [35] who reported that among teens girls were more likely of being target of cyberbullying than boys but they are at more risk of developing emotional problems as a result of cyberbullying. Among high school students in Texas, Aoyama, Talbert and Barnard-Brak [36] found girls to be more victims of cyber bullying than do boys.

Finally the research finding showed that there is a statistically significant difference in age categories on general online victimization among the participants in which Participants within age categories of 16-20 years have higher mean scores in general online victimization than age categories 13-15 years. This suggests that the older students experience more general online victimization experience [36], [37].

\section{CONCLUSIONS AND RECOMMENDATIONS}

Based on the findings of this study, authors conclude that there is a high prevalence of child exposure to domestic violence, depression and cyber bullying among Nigerian secondary school students, and that CEDV is a positive correlate of depression and cyber bullying among the adolescents. As a signatories of the United Nations International Children Emergency Fund (UNICEF) child right act, Nigeria is under the obligation to protect children. Consequently policies on domestic violence that directly or indirectly affect the child, abuses targeted at children, neglect and maltreatment as well as their attendant consequences on the child's mental health and subsequent influence on behavior should be widely publicized and enforced.

\section{ETHICAL CONSIDERATIONS}

Permission of the school authorities was sought and obtained before the instruments were administered. Also the purpose of the research was explained to the participants and their consents obtained. The participants were not forced to take part in the study also no name was written and hence confidentiality was ensured.

\section{REFERENCES}

[1] B. Belsey. "Cyberbullying." Retrieved from www.cyberbullying.ca [Google Scholar]). According to Willard (2004aWillard, N. (2004a). An educator's guide to cyberbullying and cyberthreats2004. Retrieved from http://cyberbully.org/docs/cbcteducator.pdf.
[2] J. W. Patchin, and S. Hinduja, S. "Bullies move beyond the schoolyard: A preliminary look at cyberbullying". Youth Violence and Juvenile Justice, vol 4 no 2 pp 148-169, 2006.

[3] N. Willard, Educator's guide to cyberbullying: Addressing the harm caused by online social cruelty. Retrieved from http://www.asdk12.org/MiddleLink/AVB/bully_topics/EducatorsGuide _Cyberbullying.pdf 2004.

[4] T. Beran and Q. Li. "Infusion technology into a mathematics methods course: Any impacts?". Educational Research, vol.47(2) pp 217-233 . 2005.

[5] World Health Organization (WHO). Addressing violence against women and achieving millennium development goals: WHO/FCH/ CWH/05.1 (http;//www.who.int/gS.ender/ 2005.

[6] United Nations International Children's Emergency Fund (UNICEF). Domestic violence against children. References, page 882007 (www.unicef.org/sowc07/docs/sowc07_panel_2_1.pdf).

[7] R. A. C. Siemieniuk, H. B. Krentz,, J.A. Gish; and M. J. Gill, "Domestic Violence Screening: Prevalence and Outcomes in a Canadian HIV Population". AIDS Patient Care and STDs vol. 24 nol2 pp. 763-770, 2010.

[8] H. Heidi "A Feminist Reading of Security in Africa”, 20 Caring security in Africa, pp. 126-131, 1998.

[9] A. A. Adebayo, and T. O. Kolawole, "Domestic Violence and Death Women as Endangered Gender in Nigeria" American Journal of Sociological Research. Vol. 3 no.3, pp.53-60, 2013.

[10] L. W. Dodd. "Therapeutic groupwork with young children and mothers who have experienced domestic abuse". Educational Psychology in Practice vol.25pp. 21-36. doi:10.1080/02667360802697571. 2009

[11] A. Lazenbatt and M .E Thompson-Cree. "Recognizing the cooccurrence of domestic and child abuse: A comparison of communityand hospital-based midwives". Health \& Social Care in the Community 2009 17(4): 358. doi:10.1111/j.1365-2524.2009.00833.

[12] C. Sadeler. "An ounce of prevention: The life stories and perceptions of men who sexually offended against children" (M.A. thesis) Wilfrid Laurier University. 1994.

[13] Y. Cao, L. Li, X. Zhao, Y. Zhang, X. Guo, Y. Zhang and X. Luo, "Effects of exposure to domestic violence on children's behavior: A Chinese community-based sample". Journal of Child \& Adolescent Trauma, vol.9 no. 2 pp. 127-135, 2016.

[14] R. C. Hiremath and S. P. Debaje, "The prevalence of domestic violence and mental health profile of adolescents exposed to domestic violence in an urban slum in Mumbai". International Journal of Research in Medical Sciences, vol. 2, no. 1, 2017.

[15] S. M. Billah and F. Khan. "Depression among urban adolescent students of selected secondary schools." Faridpur Med. Coll. J. 2015; vol. 9, no. 2, pp.73-75

[16] J. L. Edleson, "Child exposure to domestic violence, (CEDV)" Minnesota Center Against Violence and Abuse, School of Social Work University of Minnesota 1404 Gortner Avenue St. Paul, MN 551086142,2007

[17] M. M. Weissman, H. Orvaschel and N. Padian, " Children's symptom and social functioning self-report scales: Comparison of mothers' and children's reports. Journal of Nervous Mental Disorders 1980 vol.168 no.12, pp.736-740.

[18] B. M. Tynes, C.A. Rose, and D.R. Williams, "The Development and Validation of the Online Victimization Scale for Adolescents". Cyberpsychology: Journal of psychosocial research in cyberspace, vol $4, \quad$ no.2 article 2 retrieved from http://cyberpsychology.eu/article/view/4237/3282.

[19] J. M. Chinawa, P. C. Manyike, H. A. Obu, A, E. Aronu, O. Odutoa and A.T. Chinawa, "Depression among adolescents attending secondary schools in southeast Nigeria" Annals of African Medicine, vol.14, pp. 46-51, 2018.

[20] C. Umeh. "Depression among secondary school students in Nigeria": a comparative analysis of southwest and southeast secondary school students in Nigeria. Unpublished PhD Thesis. 2018.

[21] F. E. Okwaraji, E. N. Aguwa, G. C. Onyebueke, and C. Shiweobi-Eze, "Assessment of internet addiction and depression in a sample Nigerian university undergraduates". International Neuropsychiatric Disease Journal vol.4 no.3 pp. 114-122, 2015; Article no.INDJ.2015.033 ISSN: 2321-7235.

[22] K. K. Jha, S. K. Singh and N. Aggrawal, "Depression among schoolgoing adolescents in an urban area of Bihar", India. International Journal of Research in Medicine, vol. 6 no. 8 pp. 2813-2817, 2017.

[23] K. S. Kumar and B. S. Akoijam, "Depression, anxiety and stress among higher secondary school of Imphal", Manipur. Indian Journal of Community Medicine, vol. 42, pp. 94-96, 2018

[24] M. Ramli, S. Adlina, A. Suthahar, A. B. Edariah, F. M. Ariff, A. H. H. Narimah, A. S, Nuraliza, I, Fauzi and C. Karuthan, "Depression among secondary school students": a comparison between urban and rural 
populations in a Malaysian community. Journal of Psychiatry, vol. 8 no2 pp. 82-89, 2017.

[25] D. Barrio, M. J. Dios, I. Montero, E. Martin, E. Ochaita, M. A. Espinosa, H. Y. Gutierrez and A. Barrios, "Cyberbullying among Spanish secondary school students". 15th European Conference on Developmental Psychology 2018.

[26] Y. Bulut and B, Alci. "Cyberbullying among secondary school students". Kalemacademy.com,.2014.

[27] T. Safaria, The prevalence and impact of cyberbullying in a sample of Indonesian junior high school students. TOJET, July 2016, vol. 15, no. 3.

[28] C. N. Kingsley, C. N. Ementa and P. E. Ejikeme. "Cyberbullying among Nigerian students: awareness and incidence". Romanian Journal of Psychological Studies, 2018 vol. 6, no.1

[29] D. Owuamanam and V. I. Makinwa "The prevalence of bullying among secondary school students in Ondo state, Nigeria". European Scientific Journal, vol. 11, no. 20, 2015.

[30] D. J. Flannery, K. L. Wester and M. I. Singer, "The impact of exposure to domestic violence on children and adolescents mental health". Journal of Community Psychology, vol. 325 pp. 559-573, 2014.

[31] N. A. Amazu and P. I. Enang, "Domestic abuse and behavioral problems among students in Aba", Abia state Nigeria. Asian Research Journal of Arts \& Social Sciences, vol. 5 no. 4 pp. 1-8, 2018.

[32] B. G. Edwards, “Children's Exposure to Domestic Violence”. Children exposed to domestic violence may experience a range of difficulties. 2019, Febuary 26.

[33] C. Kothari, (2018): "The Link Between Bullying and Domestic Violence". Accessed $16^{\text {th }} \quad$ August 2019 from http://www.mariposarespect.org/pdf/The\%20Link\%20Between $\% 20 \mathrm{Bul}$ lying\%20and\%20Domestic\%20Violence.pdf.

[34] T.J. Borchard, "Why do women get depressed more than men". $8^{\text {th }}$ July 2018.

[35] J. Maclean, "Girls more likely to be victims of cyberbullying than boys, finds Canadian study". 2017.

[36] I. Aoyama, T. Talbert and L. Barnard-Brak "Cyberbullying among high school students in Texas". Cyberbullying in the Global Playground, 2011 pp. 183-201.

[37] D. Hango, Insight on canadian society . cyberbullying and cyberstalking among internet users aged 15 to 29 in canada. Symbol of statistics Canada. 2016. Retrieved June 25, 2020 from https://www150.statcan.gc.ca/n1/pub/75-006-x/2016001/article/14693eng.htm. 
